\title{
Guided Quick Labs and Academically Challenged Learners' Predicting, Observing, and Inferring Skills
}

\author{
Martin John M. Salanatin \\ Antique National School, Antique, Philippines \\ mjsalanatin@yahoo.com \\ https://orcid.org/0000-0003-1830-8946
}

\begin{abstract}
This quasi-experimental study aimed at determining the effects of guided quick labs and traditional science laboratory activities on academically-challenged Grade 10 learners' predicting, observing, and inferring skills. The subjects in this study were the 60 academicallychallenged Grade 10 learners of Antique National School in San Jose, Antique. The subjects were divided into two groups, the traditional and the quick labs. Pretest and post-test ware used to measure the predicting, observing, and inferring skills of the learners before and after exposure to both laboratory activities. The results showed that the predicting, observing, and inferring skills of the academicallychallenged Grade 10 learners in both groups were comparable at the start of the six (6)-week intervention. After the intervention, the results revealed that both groups were still comparable. The findings proved that both types of laboratory activities have a similar effect in predicting and observing skills and is best improving the learners' inferring skills.
\end{abstract}

Keywords: Education, Guided Quick Labs, Academically Challenged Learners, Predicting, Observing, Inferring, QuasiExperimental, Antique

Date Submitted: March 29, 2020

Date Revised: June 10, 2020

Date Accepted: June 15, 2020

\subsection{Introduction}

Science in the curriculum has always been given priority because of the significant influence of science in everything people do and inseparable from other curricular offerings in secondary education. The teaching of science is important as a subject itself because the students' learning capacity is influenced by the way the concepts and contents of the lessons are taught (Loughran, 2000).

With the advent of science revolution in Asia and the country, the current trend in science teaching is characterized by new creations and ingenious systems of doing things (Khine, 2015). The present educational set-up has to set the right 
direction and suitable teaching and learning conditions for educators to be ready and capable in meeting consequent challenges and as opportunities for urgent reforms (DOST-SEI, 2015).

One study of Friensen and Scott (2013) states that science teaching is developing students' ability to identify the truth and validating information through the use of basic and integrated science process skills. In their daily living, students react and interact with various experiences prevailing in the environment, as well as on innate elements prevailing in the environment. Their response depends on their innate skills in employing a method of finding out the "what" and the "how" to answer such a demand (Yockey, 2001).

Science process skills are essential skills, wherein scientists are using it when they study or investigate something. Among the thinking skills used by scientists are observing, classifying, communicating, measuring, inferring, and predicting. Doing either learning or teaching science is still an experience of the wonders of science. Being able to familiarize these science process skills will help students' develop critical thinking that is fostered in every science program (Rezba et al., 1995).

In the realization of this objective, schools are often hampered by one major problem, the below academic performance of the students in science and technology. Many students experience difficulty in science subjects due to a lack of understanding of the methods of science (McPherson, 2001).

Most science teachers are aware that science is better taught and learned through the practical work approach in which learners are exposed to hands-on-mindson activities (Macugay \& Bernardo, 2013). However, science teachers in the country have expressed continuously and cited the lack of materials in their schools as the main reason that deters them from conducting science laboratory activities. This, in turn, hampers the development of the students' manipulative and science process skills such as predicting, observing, and inferring.

As observed, academically challenged students to have short attention spans and easily get bored with long science experiments. Hence, teachers are challenged to come up with laboratory activities that will enable students to see interesting, and "eyepopping" results quickly. With several factors that hinder the students from performing well in class, such as peer pressure, poverty, and other vices, students that have a short attention span often perform poorly in school (Stash, 2014).

Most public high schools do not have adequate science equipment and materials, such as laboratory apparatuses and chemicals that students can use in their hands-on activities (Orleans, 2007). Also, many science teachers have difficulty in conducting hands-on activities, like laboratory experiments, due to the unavailability of necessary tools and equipment and sufficient time to finish the activity. This is because science laboratory activities require many materials and are time-consuming. With this situation, academically challenged students who have a short attention span lose their interest in science (Rosegard \& Wilson, 2013).

The paper intended to create a contextualized type of laboratory activities which can be done in a short period and require less and simple materials that could catch the attention of students, and improve their predicting, observing and inferring skills that could further enhance their interest in learning and loving science. 


\subsection{Framework of the Study}

The foundation of science education is scientific literacy, and the development has to do with the science teaching itself through the use of discovery, demonstration, practical work, and hands-laboratory work.

The present study is anchored on the Constructivist Learning theory by Jean Piaget, which views that all learning is based on the interpretation of phenomena, situations, and events, including classroom instruction through the perspective of the learners' existing knowledge. The constructivist approach believes in the importance of students' prior knowledge, wherein they can construct meaning based on their present experiences from their past. This means that students may bring along with them prior knowledge, misconceptions, preconceptions, and alternative ideas when they enroll in secondary science. The students had acquired prior knowledge based on their experience before they had studied high school (Gee, 2012).

The constructivist perspective of learning views learners as active participants in the learning process (Bentillo, 1996, cited in Pallon, 2009). The main tenet of constructivist learning is that people construct their understanding of the world, and in turn, their knowledge. In a constructivist classroom, teachers feel more confident facilitating learning and getting the students to develop and use such science processes as observing, questioning, and inferring. Learning through these processes takes time. They require that a teacher be knowledgeable in the subject and can model how a beginning scientist develops meanings or uses and generates ideas (Ibe \& Ogena, 1990, cited in Paningbatan et al., 2004).

Hence, this study aimed at proving the thesis that guided quick lab activities (GQLA) that can be done in a short period using simple and readily available materials is a good alternative to the traditional science laboratory activities in developing academically challenged junior high school students' predicting, observing and inferring skills.

\subsection{Materials and Methods}

The quasi-experimental design was used in the study. This method involves collecting data in order to test the hypotheses or answer questions concerning the predicting, observing, and inferring skills of the academically-challenged grade 10 learners. Quasi-experimental designs are nearly the same as the true experimental design, except that the former does not have restrictions of random assignment (David, 2002).

The subjects of this study were 60 academically-challenged grade 10 learners from two different classes of Antique National School with a second grading grade of 79 and below in Grade 9 Science. Thirty students from each class to compose the treatment groups were matched-paired based on their second grading grade in grade 9 Science. The kind of laboratory activity that was used in each group was randomly selected using a toss coin.

The two groups - guided quick labs and traditional - were both exposed to identical teacher-lecture discussions to acquire understanding and concepts. However, they had differed on the kind of laboratory method used. One group used the guided quick lab, which is the experimental group, and the other group was exposed to traditional science laboratory activities that can be found in the grade 10 science learners' module. 
Before the intervention, the subjects were given a pretest. The Predicting, Observing, and Inferring Skills Inventory (POISI) was composed of ten multiple-choice items for Predicting skills, ten multiple-choice items for observing, and another ten items for inferring skills. The content of the test focused on topics about earth science, physics, chemistry, and biology, parallel to the post-test.

During the eighth-week intervention, subjects in the experimental group were exposed to Quick labs. In contrast, subjects in the control group were exposed to traditional Science laboratory activities, focusing on the same science topic/concept.

Two (2) quick labs and two (2) traditional laboratory activities were conducted per week. Before each laboratory activity, a pre-activity discussion was conducted to discuss the basic science concepts related to the activity. The subjects worked by triads on each activity. However, each student was required to fill in the activity sheet independently, which was collected before dismissal.

The subjects predicting, observing, and inferring skills were quantified based on their solutions and representation of the given problem using a rubric.

The tentative draft of the instrument underwent expert validation. Likewise, separate lesson guides and activity guides for guide quick labs and traditional groups were validated by experts.

In gathering the data, the approval of the School Principal and parents permit was secured before the conduct of the study. The subjects were oriented about the purpose and the scope of the study, the kinds of laboratory experiments, the skills inventory, and, most notably, the affirmation of their willingness to participate in the study. The researcher secured the informed consent form of the participants. They were assured of full confidentiality. The materials derived from them were disposed of by manual shredding.

Several statistical tools were utilized for data analysis. For descriptive problems concerning the predicting, observing, and inferring skills, mean was used. For inferential analysis of data, in identifying the significant difference in the predicting, observing and inferring skills of academically challenged students exposed to guided quick labs and traditional science laboratory activities, t-test for independent samples was used to determine the significance of the difference in the predicting, observing and inferring skills of junior high school students exposed to the two types of laboratory activities. Pearson's product-moment correlation was utilized to ascertain the significance, strength, and direction of the relationship among the predicting, observing, and inferring skills of the subjects. On the other hand, in order to determine the type of observations that the subjects have made, the written observations were classified and tallied.

\subsection{Results and Discussion}

Predicting, Observing, and Inferring Skills of Academically-Challenged Grade 10 Learners Before and After Exposure to Guided Quick Lab Activity and Traditional Science Laboratory Activities

Before the intervention was conducted, the data gathering instrument, Predicting, Observing, and Inferring Skills Inventory (POISI), was administered as 
a pretest to the subjects in the Guided Quick Lab (GQL) and Traditional Science Laboratory (TSL) groups. The results in Table 1 reveal that the subjects in both groups have "proficient" predicting skill, that is -for the GQL group $(M=6.14, S D=2.05)$ and the TSL group ( $M=6.24, S D=2.15)$. The standard deviation (SD), which ranged from 2.02 to 2.15 , indicates the slight dispersion of each group's scores. Subjects in the GQL group had "advanced" observing skills $(M=8.24, S D=1.33$ while those in the TSL group had "proficient" observing skills $(M=7.70, S D=1.70)$. The standard deviation, which ranged from 1.33 to 1.70 , indicates the homogeneity of the scores for each group. The inferring skill of the GQL group was "approaching proficiency" ( $M=4.37, \mathrm{SD}=2.03)$. The standard deviations, 1.87 to 2.03 , indicate a slight dispersion of the scores for each group.

The academically challenged Grade 10 learners have already acquired some science process skills in their lower grades since they already have science subjects from elementary to Grade 9. Gee (2012) stated that students already have prior knowledge of how things work, and children gradually developed cognitive structures to understand his environment (Diaz, 2017). Before entering school, they already have with them alternative ideas about how things work and about themselves and others. $A$ positive correlation has been established between students' prior knowledge and their ability to apply higher-order cognitive skills in conceptualizing experiments (Siswa et al., 2018). Ango (2002) added that a suitable type of science process skills is already taught and studied in the early years of primary school. These basic skills are considered a prerequisite to learning integrated skills. The young students can be allowed to observe, handle things, and explore the environment.

Table 1. Predicting, Observing, and Inferring Skills, Before and After Exposure

\begin{tabular}{|c|c|c|c|c|c|c|c|c|}
\hline \multirow{3}{*}{ Skills } & \multicolumn{8}{|c|}{ GUIDED QUICK LABS } \\
\hline & \multicolumn{4}{|c|}{ Before Exposure } & \multicolumn{4}{|c|}{ After Exposure } \\
\hline & $\mathrm{n}$ & $\mathrm{M}$ & SD & Description & $\mathrm{n}$ & $\mathrm{M}$ & SD & Description \\
\hline Predicting & 30 & 6.14 & 2.05 & Proficient & 30 & 6.84 & 2.29 & Proficient \\
\hline Observing & 30 & 8.24 & 1.33 & Advanced & 30 & 8.43 & 1.41 & Advanced \\
\hline Inferring & 30 & 4.37 & 2.03 & Approaching & 30 & 6.34 & 2.03 & Proficient \\
\hline \multirow{3}{*}{ Skills } & \multicolumn{8}{|c|}{ TRADITIONAL } \\
\hline & \multicolumn{4}{|c|}{ Before Exposure } & \multicolumn{4}{|c|}{ After Exposure } \\
\hline & $\mathrm{n}$ & $\mathrm{M}$ & SD & Description & $\mathrm{n}$ & $\mathrm{M}$ & SD & Description \\
\hline Predicting & 30 & 6.24 & 2.15 & Proficient & 30 & 6.57 & 1.65 & Proficient \\
\hline Observing & 30 & 7.70 & 1.78 & Advanced & 30 & 8.60 & 1.43 & Advanced \\
\hline Inferring & 30 & 3.77 & 1.87 & Developing & 30 & 6.37 & 1.87 & Proficient \\
\hline
\end{tabular}

Note: 0-1.99 - Beginning; 2.00-3.99 -Developing; 4.00-5.99 - Approaching Proficiency; 6.00-7.99-Proficient; 8.00-10.00 - Advanced

\section{Differences in Predicting, Observing and Inferring Skills before and after exposure to the Guided Quick Labs Activity and Traditional Science Laboratory Activity}

The students' predicting skills did not significantly increase as a result of the intervention. This is shown by the t-test result for guided quick labs, $t(29)=-1.795, p=0.083$ and traditional $\mathrm{t}(29)=-.835, \mathrm{p}=0.448$. It indicates that the two types of laboratory activities were not effective in improving academically-challenged students' predicting skills. 
The students' observing skills before and after exposure to guided quick labs were not significantly different, $t(29)=-.769, p=0.411$, as shown in Table 2 . However, the observing skill of students who were exposed to traditional science laboratory activity, significantly increased $t(29)=-3.407, p=0.002$. This indicates that traditional science laboratory activities are more effective than the guided quick lab activities in developing the academically-challenged learners' observing skills.

The inferring skills of the subjects exposed to both kinds of laboratory activities significantly increased as a result of the intervention. This is shown by the t-test result for guided quick labs, $t(29)=-6.612, p=0.000$ and traditional $t(29)=-8.212, p=000$. This indicates that the inferring skill of the subjects exposed to the two types of laboratory activities-guided quick lab and traditional- significantly improved after the intervention.

The findings of this study affirm the result of the study conducted by Chaguna and Yango (2008). In their study, they found that students have mastered skills in measuring, classifying, and inferring compared to experimenting, observing, predicting, and communicating. Although the result shows no significant increase on two skills the predicting and observing, the slight increase with their mean scores may be an indicator that hands-on instruction is regularly incorporated in classroom instruction, can improve students' cognitive development as well as science process skills (Scharfenberg \& Bogner, 2010; Thompson \& Soyibo, 2002; Turpin, 2000; Bristow, 2000; Stohr-Hunt, 1996; Freedman, 1997, cited in Sadi \& Cakiroglu 2011). This is further supported by Turpin (2000) that emphasized that science achievement and process skills of students involved in the hands-on activity-based program are significantly better than that of students who are involved in the traditional program or program with no hands-on activities.

Table 2. Difference in the Mean Score of Skills Before and After Exposure

\begin{tabular}{|c|c|c|c|c|c|c|c|c|}
\hline Skills & Group & $\mathrm{n}$ & $\begin{array}{c}\text { Pretest } \\
\text { Mean }\end{array}$ & $\begin{array}{c}\text { Posttest } \\
\text { mean }\end{array}$ & $\begin{array}{c}\text { Mean } \\
\text { Gain }\end{array}$ & $\mathrm{df}$ & t-value & $\begin{array}{l}\text { Sig. (2- } \\
\text { tailed) }\end{array}$ \\
\hline \multirow[t]{2}{*}{ Predicting } & Quick Labs & 30 & 6.14 & 6.84 & 0.70 & 29 & -1.795 & 0.083 \\
\hline & Traditional & 30 & 6.24 & 6.57 & 0.33 & 29 & -.835 & 0.448 \\
\hline \multirow[t]{2}{*}{ Observing } & Quick Labs & 30 & 8.24 & 8.44 & 0.20 & 29 & -.769 & 0.411 \\
\hline & Traditional & 30 & 7.70 & 8.60 & 0.90 & 29 & -3.407 & 0.002 \\
\hline \multirow[t]{2}{*}{ Inferring } & Quick Labs & 30 & 4.37 & 6.34 & 1.97 & 29 & -6.612 & $0.000 * *$ \\
\hline & Traditional & 30 & 3.77 & 6.37 & 2.60 & 29 & -8.212 & $0.000 * *$ \\
\hline
\end{tabular}

Note: significant @(2-tailed) $>0.05 / * *$ highly significant @ 0.00

\section{The Difference in the Mean Gain scores in Predicting, Observing and Inferring Skills}

The t-test result in Table 3 shows that there is no significant difference in the predicting skill mean gain score between the guided quick labs and traditional groups $t$ $(58)=.657, p=.514$. Although the mean gain score of the guided quick lab group $(M=0.90)$, is higher than that of the traditional group $(M=0.33)$. Nevertheless, the difference between the two main gain scores is not statistically significant. Moreover, the mean gain in terms of the observing skill of the subjects does not also differ significantly with each other, $t(58)=-1.889, p=0.64$. On the other hand, the inferring skill of the subjects 
exposed to the traditional science laboratory activities is significantly better than that of the subjects exposed to guided quick lab activities, $t(58)=12.346, p=0.000$. This goes to show that traditional science laboratory activities are more effective than guided quick lab activities in developing the inferring skill of academically-challenged learners.

The present study shows a connection between the structured and unstructured way of conducting laboratory activities and hands-on laboratory experiments. The study of Johnstone, Watt, and Zaman (1998) revealed that students could be successful in a laboratory course even with little understanding of what they are doing. While Pennick and Yagger (1993) cited in Roth (2006) emphasized that doing laboratory activities in a hands-on manner makes learning science more interesting to students than the typical textbook-based program. Both ways of conducting laboratory activities emphasize the physical principles being taught but require different students' involvement. The structured laboratory provides step-by-step procedures, while the unstructured laboratory merely specifies the objectives and lets the students decide for the procedures to achieve desired results. Between the two types of laboratory activities, the guided quick lab is more on the unstructured side. In that case of the findings, it shows similar findings to the study of Alkan (2016), which revealed nonstatistically different results on the science achievement of students exposed to handson activities and traditional teaching activities.

Table 3. The difference in the Mean Gain scores in Predicting, Observing and Inferring Skills

\begin{tabular}{|c|c|c|c|c|c|c|c|}
\hline Skills & Group & $\mathrm{n}$ & $\begin{array}{c}\text { Pretest } \\
\text { Mean }\end{array}$ & $\begin{array}{c}\text { Posttest } \\
\text { Mean }\end{array}$ & Gain & t-value & Sig. (2-tailed) \\
\hline \multirow[t]{3}{*}{ Predicting } & Quick lab & 30 & 6.14 & 6.84 & 0.70 & \multirow{3}{*}{.657} & \multirow{3}{*}{.514} \\
\hline & & & & & & & \\
\hline & Traditional & 30 & 6.24 & 6.57 & 0.33 & & \\
\hline \multirow[t]{3}{*}{ Observing } & Quick lab & 30 & 8.24 & 8.44 & 0.20 & \multirow{3}{*}{-1.889} & \multirow{3}{*}{.064} \\
\hline & & & & & & & \\
\hline & Traditional & 30 & 7.70 & 8.60 & 0.90 & & \\
\hline \multirow[t]{3}{*}{ Inferring } & Quick lab & 30 & 4.37 & 6.34 & 1.97 & \multirow{3}{*}{-12.346} & \multirow{3}{*}{.000} \\
\hline & & & & & & & \\
\hline & Traditional & 30 & 3.77 & 6.37 & 2.60 & & \\
\hline
\end{tabular}

\section{Relationship between the Predicting, Observing and Inferring Skills}

Table 4 shows that the academically-challenged learners' predicting and observing skills are weak and not significantly correlated as indicated by the value of Pearson's' product-moment correlation coefficient, $r=0.344$ at $p=.62$. Predicting and inferring skills have a moderately significant correlation, $r=0.571$ at $p=.001$. At the same time, the observing and inferring skills of the learners also show a moderately significant correlation at $r=0.483$ at $p=.007$, when the subjects were taken as a whole group.

This implies that learners' predicting skills have a minimal association with their observing skills; that is, the learners cannot utilize their observing skills to make predictions. However, learners who are good at inferring are also good at 
predicting. Somehow, a learner with good observing skills will most likely have good inferring skills.

The present study also supports the study of Rezba et al. (1995) who stated that the ability to make good observations is also essential to the development of science process skills and observation is needed in order make correct predictions. Predicting and observing skills provides more self-correction and self-adjustment opportunities to students and gradually eliminates scientific misconceptions (Zacarhia et al., 2015; Hsiao et al., 2017). On the other hand, predicting is based on a good inference about the observed events. The more correct observations made, the more reliable inferences are.

The study of Broadway and Taillon (2001) added that inference and observation are not different in kind but rather a difference in degree. Observation is a different degree of inference and is one type of subsets of inference. An inference is an interpretation or an explanation of observation, while observation is processed using the senses. In order to make an inference, what is being observed is connected to prior knowledge, and the new information is observed through the senses. An inference can be developed from more than one observation, and it is not just a guess (Pinnell \& Scharer, 2003).

Table 4. Relationship between the Predicting, Observing and Inferring Skills

\begin{tabular}{lcc}
\hline Variable & $r$ & Sig. (2-tailed) \\
\hline Predicting x Observing & 0.344 & 0.62 \\
Predicting x Inferring & 0.571 & 0.01 \\
Observing x Inferring & 0.483 & 0.007 \\
\hline
\end{tabular}

Note: 0.0-0.19 - very weak; 0.20-0.39 -weak; 0.40-0.59 - moderate; 0.60-0.79 - strong;

$0.80-1.0$ - very strong; ${ }^{* * *} \mathrm{p}<0.001$, significant

\subsection{Conclusion}

Academically challenged learner's predicting and observing skills can be improved when they are exposed to appropriately designed laboratory activities like the guided quick labs and traditional science laboratory activities. However, the type of laboratory activities to which the academically-challenged learners are exposed does not matter as long as they are exposed continuously to inquiry-based science activities. Academically challenged learners inferring skills greatly improved after the intervention, and guided quick labs show a greater improvement compare to the traditional science laboratory activity. Therefore, guided quick labs can be used in improving students' inferring skills because they are free to manipulate. The activities involve the use of materials that can be found at home. It is not time-consuming and could catch the attention of the students easily.

Since the result of the present study revealed the same effectiveness of guided quick labs to that of traditional laboratory science activities on students predicting, observing and inferring skills, the use of guided quick labs activities is one of the choices for every Grade 10 Science teacher who teaches academically challenged learners'. Teachers who are successful in using this type of laboratory activity in their classes will 
have the satisfaction of knowing they have helped their students in preparation for their professional careers in the years to come. In the same manner, learners will benefit. They would make the learning of science subjects more encouraging, meaningful, and fun. In addition, the teachers' creativity and resourcefulness are also further developed as guided quick labs, which requires them to improvise and to look for materials that are available locally. The contextualization of the laboratory activities accelerates the progress of academically-challenged students and the practitioners who use it to observe positive results. The available quantitative evidence indicates that it has the potential to increase students' achievement.

In as much as the purpose of the two types of laboratory activities to improve the learners' predicting, observing and inferring skills, the following recommendations are deemed significant: a) Science teachers teaching academically-challenged students' may create science laboratory activities that focus in developing predicting, observing and other science process skills; b) Students may be exposed to a science laboratory facility to have hands-on experience in conducting laboratory experiments; c) School heads may provide proper laboratory equipment and facilities for students to use. Further, a parallel study may be conducted with a longer intervention period to determine the effectiveness of guided quick lab activities and traditional science laboratory activities in improving students' predicting, observing, and inferring skills. Future research may be undertaken to investigate the effectiveness of laboratory activities- guided quick lab activities and traditional science laboratory activities - on other topics in science and other learning areas. 


\section{REFERENCES}

Alkan, F. (2016). Experiential Learning: Its Effects on Achievement and Scientific Process Skills. Journal of Turkish Science Education 13(2):15-26. DOI: 10.12973/tused.10164a

Ango, M.L.,(2002), Mastery of Science Process Skills and Their Effective Use in the Teaching of Science: An Educology of Science Education in the Nigerian Context. University of Jos, Plateau State, Nigeria. International Journal of Educology, Vol 16, No 111 Retrieved on October 25, 2016, from http:// www.era-usa.net/images/011-IJE_2002_V16_N1_Ango,_Mary,_Mastery_of_Science.pdf

Bristow, G.(2002). Structure, Strategy and Space: Issues of Progressing Integrated Rural Development in Wales. Sage Journals. DOI:10.1177/096977640000700102

Broadway, F. S. and Taillon, K. (2001) Learning Science Through Reading: Fifth-Grade Students' Conceptualization of Observation and Inference. Association for the Education of Teachers in Science. Retrieved from https://files.eric.ed.gov/fulltext/ED453083.pdf\#page=411

Chaguna B. and Yango D. (2008). Science Process Skills Proficiency of the Grade Vi Pupils in the Elementary Diocesan Schools of Baguio. Research Journal, Volume XVI - 2008 Edition

David, F., (2002), Understanding and Doing Research: A Handbook for Beginners, Trial Edition. Iloilo City: Panorama Printing, Inc.

Diaz, K.,(2017). Prior Knowledge: Its Role in Learning. University of the Philippines Los Baños. DOI: 10.13140/RG.2.2.26816.69125

DOST SEI., (2015). CALIBRATED for integration. Retrieved on October 30, 2016, from http://www.sei.dost. gov.ph/images/ts/ar2015.pdf

Friensen, F. and Scott D. (2013). Inquiry-Based Learning: A Review of the Research Literature. Calgary: Alberta Ministry of Education

Gee, J. (2012). Importance of Prior Knowledge to Learning. Retrieved from Illinois State University: https:// news.illinoisstate.edu/2012/01/importance-of-prior-knowledge-to-learning/

Hsiao, H.S., Chen, J.C., Hong, J. C., Chen, P.H., Lu, C.C., and Chen, S. Y. (2017). A five-stage Predictionobservation-explanation inquiry-based Learning Model to Improve Students' Learning Performance in Science Courses. EURASIA Journal of Mathematics Science and Technology Education ISSN: $1305-8223$

Johnstone, A.H., Watt, A. and Zaman, T.U., (1998). The students' attitude and cognition change to a physics laboratory. Physics Education, 22-28

Khine, M., (2015) Science Education in East Asia Pedagogical Innovations and Research-informed Practices, Emirates College for Advanced Education, Abu Dhabi, United Arab Emirates DOI: 10.1007/978-3319-16390-1. The Netherlands: Springer

Loughran, J. (2000). Teaching about Science Teaching and Learning: research should inform practice. AsiaPacific Forum on Science Learning and Teaching, Volume 1, Issue 1, Article 1, p.1. Retrieved on October 26, 2016 form https://www.researchgate.net/publication/26411155_Teaching_about_ science_teaching_and_learning_research_should_inform_practice

Macugay E, and Allan, B.,(2013). Science coursework and pedagogical beliefs of science teachers: The case of science teachers in the Philippines. Science Education International Vol. 24, Issue 1, 2013, 6377: Retrieved on October 28, 2016 from https://files.eric.ed.gov/fulltext/EJ1015831.pdf

McPherson, G. (2009). Teaching and learning the scientific method. The American Biology Teacher. DOI: 10.1662/0002-7685(2001)063[0242:TLTSM]2.0.CO;2

Orleans, A. (2007). The condition of secondary school physics education in the Philippines: Recent developments and remaining challenges for substantive improvements. Australian Educational Researcher 34(1):33-54. DOI: 10.1007/BF03216849

Pallon, R. (2003). Science Process Skills, Attitudes, and Science and Technology Achievement of High School Students. Unpublished master's thesis, West Visayas State University, Iloilo City.

Paningbatan, D.C., Kozai, T., Ozawa, H., Morata, M., and Nishimura, H., (2004). Secondary Science Education Curriculum in The Philippines. Graduate School of Natural Science Education (Science). Naruto University of Education, Japan

Pinnell, G. S. and Scharer, P. L. (2003). Teaching for Comprehension in Reading Grades K-2. Retrieved from https://www.google.com.ph/search?tbm=bks\&hl=en\&q=\%28Pinnell+\%26+Scharer\%2C+2003+

Rezba, R. J., Sprague, C. S., Fiel, R. L., Funk, H. J., Okey, J. R., \& Jaus, H. H. (3rd Ed.). (1995). Dubuque, IA: Kendall/Hunt Publishing Company 
Rosegard, E. and Wilson, J. (2013). Capturing students' attention: An empirical study. Journal of the Scholarship of Teaching and Learning, Vol. 13, No. 5, pp. $1-20$.

Roth, K.J. (2006). Teaching Science in Five Countries: Results from the TIMSS 1999 Video Study Statistical Analysis Report.U.S. Department of Education. National Center for Education Statistics. Retrieved on October 25, 2016, from https://books.google.com.ph/books?

Sadi, O. and Cakiroglu, J., (2011) Effects of hands-on activity enriched instruction on students' achievement and attitudes towards science. Journal of Baltic Science Education 10(2) 11 Retrieved on October 25, 2016, from https://www.researchgate.net/publication/40540853_Effects_of_handson_activity_enriched_instruction_on_students'_achievement_and_attitudes_towards_science

Scharfenbeg, F.J., and Bogner, F. (2010). Instructional efficiency of changing cognitive load in an out-of school laboratory. International Journal of Science Education. DOI: 10.1080/09500690902948862

Siswa A. N. van Riesen, Hannie Gijlers, Anjo Anjewierden \& Ton de Jong (2018) The influence of prior knowledge on experiment design guidance in a science inquiry context, International Journal of Science Education, 40:11, 1327-1344, DOI: 10.1080/09500693.2018.1477263

Stash, K., (2014). The Effect of Focused Attention Span on Overall Academic Achievement. Goucher College Graduate Programs in Education. Retrieved on November 3, 2016 from https:// mdsoar.org/bitstream/handle/11603/2227/MEd_StaschKiley_actionres_Fa2014. pdf?sequence=1\&isAllowed=y

Stohr-Hunt, P. (1996). An analysis of frequency of hands-on experience and science achievement. Journal of Research in Science Teaching. Volume 33, Issue 1. Pages 101-109.

Thompson, J. and Soyibo K., (2002). Effects of Lecture, Teacher Demonstrations, Discussion and Practical Work on 10th Graders' Attitude to Chemistry and Understanding of Electrolysis. Research in Science and Technological Education 20(1):25-37es DOI: 10.1080/02635140220130902

Turpin, T.P. (2000). A study of the effects of an integrated, activity-based science curriculum on student achievement, science process skills, and science attitudes. Retrieved on October 25, 2016, from https://www.researchgate.net/publication/234204963_A_study_of_the_effects_of_an_ integrated_activity-based_science_curriculum_on_student_achievement_science_process_ skills_and_science_attitudes

Yockey, J. A. (2001). Science \& Children. An article at the elementary school level, describing a simple writing technique to help students communicate the important science concepts they have learned. Retrieved on October 26, 2016, from http://www.longwood.edu/cleanva/images/sec6. processskills.pdf

Zacharia, Z., (2015). Identifying potential types of guidance for supporting student inquiry when using virtual and remote labs in science: a literature review. Education Tech Research Dev 63, 257-302 (2015). https://doi.org/10.1007/s11423-015-9370-0 